relapse in untreated patients were $0.33,0.62$, and 0.77 and, in the treated group, $0.1,0.2$, and 0.4 , after 12,24 , and 36 months, respectively. Treated men were less susceptible to recurrence than treated women. EEG abnormalities were observed in $20 \%$ of both treated and untreated patients, and rate of seizure recurrence was not correlated with EEG epileptiform activity. Treatment consisted of carbamazepine $(10 \mathrm{mg} / \mathrm{kg} / \mathrm{day})$ in $36(80 \%)$ patients; it had to be changed to valproic acid (600-1200 mg/d) in 9 (20\%). (Gilad R, Lampl Y, Gabbay U, Eshel Y, Sarova-Pinhas I. Early treatment of a single generalized tonicclonic seizure to prevent recurrence. Arch Neurol November 1996;53:11491152). (Reprints: Ronit Gilad MD, Department of Neurology, the Edith Wolfson Medical Center, Holon 58100, Israel).

COMMENT. The age range of these patients was 18 to 50 , mean 30 years. Studies in children and adolescents might show different results. The benefits of immediate anticonvulsant treatment in these adults is apparent, but the decision to begin treatment after a single seizure must be made on an individual basis, having regard to drug toxicity on the one hand and the adverse consequences of a seizure recurrence on the other. Risk factors for recurrence of seizures, with and without therapy, require further study in children and adult populations. Previous studies have shown seizure recurrence rates varying from 33 to $80 \%$.

\title{
RASMUSSEN ENCEPHALITIS: SURGICAL BENEFITS
}

Social communication, language, and PET glucose utilization were studied before and after right hemispherectomy in four children with Rasmussen encephalitis (RE) at the University of California, Los Angeles. Improved social communication and language following surgery was related to age at onset, duration of illness, and reversibility of the hypometabolism in the nonresected prefrontal cortex. Improvements in communication and language were not accompanied by improved IQ scores. Early surgical treatment might lessen the degree of deficit in communication and language skills. Onset of RE after age 11 years is associated with less social communication deficit. (Caplan R, Curtiss S, Chugani HI, Vinters HV. Pediatric Rasmussen encephalitis: social communication. language, PET, and pathology before and after hemispherectomy. Brain Cogn Oct 1996;32:45-66). (Reprints: Dr R Caplan, Neuropsychiatric Institute, 760 Westwood Plaza, Los Angeles, CA 90024).

COMMENT. Right hemisphere damage is associated with delays in language development. Surgery performed early to control seizures prevents further deterioration in intellectual functioning and results in improved language and communication skills.

\section{CNS NEOPLASMS}

\section{PROGNOSIS OF INTRACRANIAL EPENDYMOMAS}

Grading and localization of 67 intracranial ependymomas operated on in children less than 15 years of age from 1951 to 1990 were correlated with prognosis in a retrospective study at the University of Koln, Germany. Grade II ependymomas (38) were located in the IV ventricle and supratentorial midline, making complete removal impossible. The majority of grade III anaplastic, malignant tumors (28) were in the cerebral hemispheres and were totally removed. Operative mortality was higher in grade II than grade III. Median 